\title{
Transfer Pricing In A Global Economy
}

Jin Ulmer, Angelina College, USA

Jack Ethridge, Stephen F. Austin State University, USA

Treba Marsh, Stephen F. Austin State University, USA

\begin{abstract}
In September 2006, the Internal Revenue Service and GlaxoSmithKline entered into an agreement to settle transfer pricing disputes covering the years 1989 to 2005 . The \$5.2 billion agreement, whereby Glaxo paid \$3.4 billion in back taxes plus dropped a claim for a \$1.8 billion tax refund, was the largest settlement in IRS history. ${ }^{I}$
\end{abstract}

Keywords: Transfer Pricing Taxation; Related Party Pricing

\section{IMPORTANCE OF TRANSFER PRICING}

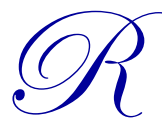

elated party pricing, or transfer pricing, is the pricing of transactions when goods or services are passed between commonly controlled entities. Although transfer pricing issues are most often discussed in the context of international taxes, transfer pricing is a common issue in almost all businesses, and not limited to large corporations. It is a fundamental accounting issue at all levels of business.

Consider, for example, inter-departmental pricing at a small business such as a plumbing company. The parts desk provides parts to the service technicians, who in turn provide plumbing services to customers. The business earns a profit. However, the question is how to allocate that profit between the parts department and the service department. Without a fair and reasonable allocation, the business owner may have a distorted picture of the profitability of the two components of his business.

In a manufacturing environment, inventory-in-progress is passed from one processing department to another, or inventory is passed from one factory to another. Often, a factory will also sell some of its products to an outside customer. Should products which are shipped to a related-party be priced the same as products shipped to an outside customer? Without a fair and reasonable internal pricing policy, the performance of both the shipping and the receiving facility could be distorted.

At the management level, bonus calculations are often based on performance metrics. In a vertically integrated business where raw materials are produced at one division and then transferred for processing to another division, management bonus calculations can be dependent on the transfer price used. Significant amounts of individual compensation can be dependent on transfer pricing decisions.

The significance of transfer pricing becomes even greater when goods are transferred from one tax jurisdiction to another. This issue is often associated with international business, but it can also be a significant issue at the state or local level. The difference in tax rates from one jurisdiction to another can (and should) have an impact on where manufacturing facilities are located, where jobs are created, and in general, where economic development occurs. Similar attributes may be attached to transfer pricing methodology since a business is highly motivated to maximize profits and to minimize tax payments.

As was highlighted by the Glaxo case, billions of dollars are riding on transfer pricing decisions. Additional risks are added because of the difficult and sometimes arbitrary allocation of taxable income between taxing jurisdictions, exposure to unfavorable tax treaties, complex and sometimes conflicting governmental regulations, and the threat of audits, penalties and double-taxation. 


\section{THE OECD}

The Organization for Economic Co-operation and Development (OECD) is the primary broker of international tax protocol. The framework established by the OECD has resulted in about 350 tax treaties between OECD member countries, and as many as 1,500 tax treaties worldwide. ${ }^{2}$

Since the OECD is almost unknown to most Americans, it is appropriate to take a closer look at this organization and how it helps shape life on the global stage. Originally founded in 1947 as the Organization for European Economic Cooperation, the OEEC was charged with managing the Marshall Plan. In 1960, with Europe essentially rebuilt from the destruction of World War II and with the obvious need for a more global approach to economic prosperity, the OEEC was reorganized and re-christened as the OECD. ${ }^{3}$

Today, the OECD has 34 member nations plus what the OECD calls "co-operative relations with more than 70 non-member economies". ${ }^{4}$ Despite the global reach of the OECD, it remains dominated by the United States and the European powers (represented by the European Commission which is the executive body of the European Union).

The OECD is headquartered in Paris, has about 2,500 employees, ${ }^{5}$ and works from an annual budget of EUR 342 million (fiscal 2011). ${ }^{6}$ About $25 \%$ of the budget is funded by the United States; all member nations contribute proportionate to their respective national economies. About 250 standing committees are maintained covering most aspects of modern life. The OECD describes itself as "a forum in which governments can work together to share experiences and seek solutions to common problems, [where] issues that directly affect the lives of ordinary people [are addressed, and] along the way, make life harder for the terrorists, tax dodgers, dishonest businessmen and others whose actions undermine a fair and open society". ${ }^{7}$ In some respects, the OECD quietly accomplishes what many people think the United Nations is supposed to, but fails to accomplish.

\section{INTERNATIONAL TAX PROTOCOL}

The core problem of international transfer pricing is allocating taxable transactions (whether revenue-based or income-based) across multiple taxing jurisdictions in an acceptable manner. ${ }^{8}$ Note that this is not purported to be a "fair and reasonable" manner, but merely "acceptable." With governments making transfer pricing an enforcement priority, the major risk to multi-national business is the risk of double taxation. Treaties based on the OECD Model Tax Convention offer protection from double taxation by establishing the protocol for allocation of taxing rights between resident and source countries, thereby allowing the resident entity to eliminate from its tax obligation amounts paid to source jurisdictions. Treaties adopting the OECD Model Tax Convention establish rules for apportioning multi-national income among the nations in which the taxpayer conducts business. ${ }^{9}$

The OECD Model adopts the "arm's-length principal" which is intended to reflect pricing as if the parties were not related. It is the cornerstone of transfer pricing methodologies used by most countries. ${ }^{10}$

\section{PROBLEMS WITH THE OECD MODEL}

While the "arm's-length principal" endorsed by the OECD Model is valid and defensible, it still has deficiencies. First, the arm's-length model is not the only valid transfer pricing model. Second, an arm's-length model may not accurately reflect the internal structure and politics of the business entity. Third, the arm's-length model may not produce the most favorable tax treatment for the business, and it may even produce problematic tax issues with the affected tax authorities. Fourth, it is not generally accepted accounting principles (GAAP).

\section{OTHER TRANSFER PRICING MODELS}

Other valid pricing models include "at-cost" pricing, "cost-plus" pricing, "modified third party" pricing, and "profit-split" pricing. ${ }^{11}$ The theory of at-cost pricing is traditional GAAP; intercompany transactions should be priced at cost, with no built-in transfer gain or loss. Any good accountant or plant manager can game this approach as easily as any other approach (by over or understating cost components, depending on the desired outcome). 
However, the theory is that no economic change occurs when goods or services are exchanged internally. For example in a plumbing company, it could be argued that no economic change occurred when the plumbing part was removed from the storeroom and placed in a bin on the service truck. When the part is eventually used on a customer's job, the part will be billed to the customer, and the business will record the sale. But which department gets credit for the sale?

The cost-plus approach takes the position that, while retail price is obviously unrealistic for internal transfer pricing, at-cost pricing is just as unrealistic. The cost-plus approach takes the position that "cost" establishes a floor value, and "retail" (i.e., arm's-length) establishes a ceiling. The correct transaction value lies somewhere in between, typically at a percentage added to a pre-determined cost amount. The percentage add-on would be justified by a study of profit margins, usually both within the business entity and margins reported by similar entities or competitors. $^{12}$

When the pricing issue involves a business unit that sells to both arm's-length and internal customers, the modified third party approach may best represent the true economics of the enterprise. This approach uses the price earned from outside sales as the benchmark, and then reduces (modifies) that price based on the fixed cost component of cost embedded in the product. The theory is that the fixed costs of owning/operating the facility are present regardless of the volume of sales, and regardless of the existence or absence of internally transferred products. Fixed costs, therefore, should be excluded from the cost structure when determining a transfer price. ${ }^{13}$

Each model has validity and each model has its deficiencies. In every case except with the at-cost model, there is a consolidation issue whereby profits embedded within the transfer price must be tracked and eliminated from the consolidated financial statements. Management may choose to use one of the competing models for internal performance evaluation, while the tax department would adjust cross-border transactions to conform to the OECD Model. Domestic transfer transactions (i.e., the related-party transfer of goods or services across domestic taxing jurisdictions) may adopt even another method of transfer pricing in order to minimize state and local tax liability. Conceivably, a multi-national entity could legitimately use several conflicting transfer pricing models for the same transactions in order to achieve multiple financial reporting objectives.

\section{STRUCTURAL AND POLITICAL CONSIDERATIONS}

Arm's-length transfer pricing is a compromise, and a compromise which seldom reflects the best interests of all parties. Instead, it is a lowest-common-denominator approach to dispute resolution. When international political relations are embedded into an issue, the magnitude and consequences are magnified. Business decisions may be made at the diplomat level instead of in the board room. Transfer pricing (and the resulting allocation of income for tax purposes) becomes a vital element of the negotiation process, with the Department of State, the Internal Revenue Service, and their foreign counterparts participating in the transfer pricing agreement.

A negotiated political agreement often will not accurately reflect the realities of operating the affected business. When operational needs conflict with political conveniences, something must be done to address those needs. One solution is to adopt a different costing/pricing methodology for operational purposes. In doing so, performance metrics can be preserved for operational purposes. The obvious disadvantage is that separate accounting must be maintained in order to both comply with the pricing agreement and produce useful operational financial information.

\section{COST SHARING AGREEMENTS}

The traditional approach to transfer pricing has been for the related parties to enter into a cost sharing agreement (CSA). A CSA is a legal document whereby costs, revenues, and the resultant income are allocated. Since a cost sharing agreement is typically executed prior to conducting business, it is frequently based on prospective values. Typically one of the parties is governed by GAAP while the other party (or parties) is governed by International Financial Reporting Standards (IFRS), creating differences in accounting and financial reporting. The allocation of intangibles such as R\&D costs, expense recognition with respect to capitalization and depreciation, and issues concerning accounting for share-based compensation are typical issues addressed in a CSA. Further, 
since the document is prospective, it is probable that actual results may differ significantly from those originally projected when the CSA was executed.

It is noteworthy that, while a CSA is a starting point, and it is the foundation of a bi-lateral Advance Pricing Agreement (discussed below in connection with the Internal Revenue Service's efforts to manage transfer pricing issues), a CSA by itself carries little weight with the taxing authorities. The facts and circumstances will prevail in tax court.

\section{INTERNAL REVENUE SERVICE REGULATIONS}

The issue of transfer pricing is not new to the IRS. In 1991, the IRS established the Advance Pricing Agreement Program (APA Program) intended to foster a cooperative approach to settling transfer pricing issues. ${ }^{14}$ Today, the APA Program is administered by the Office of the Director, Transfer Pricing Operations. ${ }^{15}$ The IRS describes the program as follows:

"The Advance Pricing Agreement (APA) Program is designed to resolve actual or potential transfer pricing disputes in a principled, cooperative manner, as an alternative to the traditional adversarial process. An APA is a binding contract between the IRS and a taxpayer by which the IRS agrees not to seek a transfer pricing adjustment for a covered transaction if the taxpayer files its tax return for a covered year consistent with the agreed transfer pricing method."

Section 482 of the Internal Revenue Code addresses transfer pricing. Proposed regulations were issued in 2004 , temporary regulations were issued in 2008 , and what appears to be the last of the final regulations, addressing section 482-7, were published on March 19, 2012 in Internal Revenue Bulletin No. 2012-12. The IRS states the purpose of section 482 is:

"...to ensure that taxpayers clearly reflect income attributable to controlled transactions, and to prevent the avoidance of taxes with respect to such transactions. Section 482 places a controlled taxpayer on a tax parity with an uncontrolled taxpayer by determining the true taxable income of the controlled taxpayer ... including controlled transactions involving loans or advances, services, and property, ... [and] provides examples illustrating the application of the best method rule." [bold italics added]

There are three concepts incorporated into section 482 which are the "controlled taxpayer," the objective of "tax parity", and the IRS approach to transfer pricing which is dubbed the "best method rule."

The concept of "controlled taxpayer" as distinguished from the "uncontrolled taxpayer" refers to the intercompany nature of internal transfer pricing. The same taxpayer controls both sides of the transfer pricing transaction which, by definition, is not at arm's length. The second concept of "tax parity" advances the IRS's goal of creating a fair playing field for all taxpayers engaged in a similar line of business. The idea is to prevent one party from obtaining an unfair advantage over another by gaming the tax payment system. The third concept of the "best method rule" establishes the IRS's methodology for establishing values for cross-border transactions. While the first two concepts establish the good intentions of the IRS, it is the best method rule which is of the most interest to the administration of a legal and acceptable transfer pricing process.

Section 482-1(c) defines the best method rule as follows, but it is not nearly the precision that accountants would like to see:

“(c) Best method rule-(1) In general. The arm's length result of a controlled transaction must be determined under the method that, under the facts and circumstances, provides the most reliable measure of an arm's length result. Thus, there is no strict priority of methods, and no method will invariably be considered to be more reliable than others. An arm's length result may be determined under any method without establishing the inapplicability of another method, but if another method subsequently is shown to produce a more reliable measure of an arm's length result, such other method must be used. Similarly, if two or more applications of a single method provide inconsistent results, the arm's length result must be determined under the application that, under the facts and circumstances, provides the most reliable measure of an arm's length result." 
As with so many federal income tax issues, the guidance in the Internal Revenue Code applicable to transfer pricing circles right back to our starting point, which in this case is the Advance Pricing Agreement Program. Without an APA, no taxpayer can rely on their methodology used to record transactions involving relatedparty pricing.

\section{THE ADVANCE PRICING AGREEMENT PROGRAM}

Since the only safe zone in the arena of transfer pricing seems to be obtaining an APA, it is appropriate to examine the process for obtaining one, but it is important to understand that the "safety" afforded by an APA may apply only to IRS treatment. There is always another taxing authority in a transfer pricing transaction, and that other taxing authority may or may not agree to the APA negotiated by the IRS.

Obtaining an APA is expensive. The unofficial base price (the filing fee) to accompany an APA application to the IRS is $\$ 50,000,{ }^{16}$ however costs of internal administrative work, consulting fees, legal assistance, travel, and final fees paid to the IRS (and also to another taxing authority) can significantly exceed the base filing fee. ${ }^{17}$ The IRS, however, has determined that compliance with section 482 is "not a significant regulatory action [because] ... few small entities are expected to enter into cost sharing agreements [covered by an APA]". ${ }^{18}$ In other words, the IRS is saying that only large multi-national businesses (who presumably can afford the expense) will have occasion to apply for an APA, so the high cost will not be an encumbrance to small businesses. Although this IRS presumption is patently unrealistic, the Small Business Administration, when asked to comment on the impact of section 482 on small businesses, supported their cousins at the IRS by offering no comments. ${ }^{19}$

The IRS encourages taxpayers to establish a bilateral APA which binds not only the IRS, but also the offshore taxing. The IRS recognizes and seeks to work within the arm's length standard established by the OECD. However, the IRS also clearly states that bilateral agreements are not always possible, and a unilateral agreement, while providing comfort for filings with the IRS, will not provide comfort to the taxpayer in other tax jurisdictions, and will not protect the taxpayer from exposure to double taxation. ${ }^{20}$ This risk is present even when the offshore country is a U.S. treaty partner.

While there are several pricing methods in the regulations deemed to be acceptable in specific circumstances, the basis of the APA system is to identify comparable prices and comparable transactions. This is the foundation of the arm's length transaction- identifying and agreeing to comparable prices and comparable transactions.

However, it is also where the most disagreement occurs, and ironically, it is not always the taxpayer who is the disagreeable party. Consider the Glaxo case which resulted in the landmark $\$ 5.2$ billion settlement with the IRS. Glaxo held patents in the U.K. for its blockbuster ulcer drug Zantec. Research and development was based in the U.K., and Glaxo maintained that it was the R\&D program (based in the U.K.) which added the true value to the drug. Therefore, Glaxo shifted cost to its U.S. group by charging high licensing fees which were paid to its U.K. division. The result was that higher cost (and lower income tax) was accrued to its U.S. division, while higher income (and more income tax) was accrued to its U.K. division. ${ }^{26}$

The IRS disagreed, contending that it was Glaxo's aggressive marketing in the U.S. which had generated all the sales, thus more of the value, thus more of the income. Not insignificantly, there was no APA in effect for the transactions challenged in the Glaxo case. Ultimately, the IRS prevailed and recovered billions of dollars, but taxes had already been paid to the U.K. based on Glaxo's original position. Part of the settlement included a partial recovery from overpayment of U.K. taxes. This case emphasizes the fact that transfer pricing is an issue which often traps a business between two countries competing for a bigger share of tax payments. The stakes are high, and governments are not willing to quickly concede anything, as evidenced above by the additional 2 years on average needed to negotiate a bilateral APA. 


\section{WHAT THE FUTURE HOLDS}

Although transfer pricing has always been an issue at large multi-national companies, events of the last 30 years are quickly pushing transfer pricing to the forefront. First, the globalization of the economy has made international transfer pricing an issue for medium sized and many small businesses. Second, decades of irresponsible government spending has pushed many nations to the brink of default. Third, the public stigma of offshore tax shelters and multi-national enterprises accused of paying little or no taxes are easy political targets. Today, with governments desperate for revenue, the tax opportunities represented by transfer pricing are enormous, irresistible, and politically attractive. Expect more aggressive pursuit of transfer pricing issues from all nations. The challenge for business managers and their accountants is to adequately prepare to support their income tax claims.

State and local governments are beginning to examine the revenue opportunities afforded by transfer pricing. While the traditional issue of transfer pricing centers on the intercompany allocation of income taxes at the federal level, the same concepts may be applied to sales tax at the state and local level. Recently, the State of Texas and Amazon settled a long-running dispute concerning sales tax charged on out-of-state mail order sales shipped from an in-state distribution center. Although this example is not traditionally considered to be a transfer pricing issue, in a broader sense, Amazon had sought to transfer the point of sale away from the Texas distribution center to the customer's delivery address located outside the State of Texas. Within the context of sales tax, this is certainly a transfer pricing issue. Expect more aggressive sales tax collection enforcement. The challenge for business managers and their accountants is to understand the law and ensure that it is correctly applied within their business at the point of sale.

These are examples of what lies ahead in the field of transfer pricing. The Glaxo case was an example of the significance of transfer pricing, but it is only one of countless examples. While the emphasis until now has been on large multi-nationals at the federal level, in the future we can expect similar scrutiny and aggressive enforcement at the state and local level. The challenge for accountants is to understand the law, document affected transactions, and to protect their employers or clients from enforcement actions through training, compliance and documentation.

\section{AUTHOR INFORMATION}

Jin Ulmer, Angelina College, 401 Crown Colony Dr, Lufkin, TX 75901. E-mail: jinu@ @ftwd.net

Jack R. Ethridge is the Temple-Inland Employees Distinguished Professor of Accounting in the Gerald W. Schlief School of Accountancy at Stephen F. Austin State University in Nacogdoches, TX. His areas of interest are auditing and financial. E-mail: jethridge@sfasu.edu

Treba A. Marsh, professor, is the director of the Gerald W. Schlief School of Accountancy at Stephen F. Austin State University. Her areas of interest are governmental, financial and auditing. E-mail: tmarsh@sfasu.edu (Corresponding author)

\section{FOOT NOTES}

1. $\quad$ irs.gov/newsroom IR-2006-142 September, 11, 2006. "IRS Accepts Settlement Offer in Largest Transfer Pricing Dispute".

2. $\quad$ oecd.org/about "Center for Tax Policy and Administration".

3. $\quad$ oecd.org/history "About OECD - History".

4. $\quad$ oecd.org/document/25 "Members and Partners".

5. oecd.org "About the OECD Secretariat".

6. $\quad$ oecd.org "Budget".

$7 . \quad$ oecd.org "Our Mission".

8. $\quad$ oecd.org "OECD Model Tax Convention".

9. Ibid.

10. Ibid.

11. tpanalytics.com/tp-reference/learning-resources/transfer-pricing-methods TP Analytics Limited, 2011. 
12. Journalofaccountancy.com/issues/1998/jul/carter "The Problems of Transfer Pricing: When You Have Facilities in More Than One Tax Jurisdiction" by William K. Carter, David M. Maloney and M.H Van Vranken, Journal of Accountancy, July 1998.

13. tpanalytics.com/tp-reference/learning-resources/transfer-pricing-methods TP Analytics Limited, 2011.

14. ey.com/gl/en/services/tax/international-tax/guide-to-advance-pricing-agreements "Guide to Advance Pricing Agreements (APA) Ernst \& Young, 2010.

15. irs.gov/irb/2010-15_irb/ar11 “Announcement and Report Concerning Advance Pricing Agreements" Internal Revenue Bulletin: 2010-15 April 12, 2010, Announcement 2010-21, Internal Revenue Service, March 29, 2010.

16. ey.com/gl/en/services/tax/international-tax/guide-to-advance-pricing-agreements

17. Ibid.

18. Internal Revenue Bulletin No. 2012-12. "Final regulations under IRC Section 482: Methods to Determine Taxable Income in Connection With a Cost Sharing Agreement”, page 505, March 19, 2012.

19. Ibid.

20. $\quad$ irs.gov/irb/2010-15 irb/ar11 "Announcement and Report Concerning Advance Pricing Agreements" Internal Revenue Bulletin: 2010-15 April 12, 2010, Announcement 2010-21, Internal Revenue Service, March 29, 2010.

21. Ibid.

22. Ibid.

23. Ibid.

24. Ibid.

25. Ibid.

26. cfo.com/article.cfm/301217 "Haven or Hell: The IRS want to crack down on multinational corporations that transfer U.S. intellectual property to tax havens” by Ronald Fink, CFO Magazine, March 1, 2012. 


\section{NOTES}

